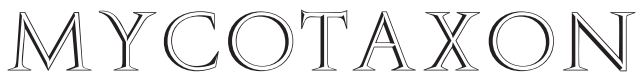

ISSN (print) 0093-4666 (online) 2154-8889 Mycotaxon, Ltd. @2017

October-December 2017-Volume 132, pp. 707-721

https://doi.org/10.5248/132.707

\title{
Russula vinosoflavescens sp. nov., from deciduous forests of Northern Alsace, France
}

\author{
Jean Michel Trendel ${ }^{1}$, Felix Hampe $^{2} \&$ Annemieke Verbeken $^{2 *}$ \\ ${ }^{1} 7$ rue des Coquilles, 67500 Haguenau, France \\ ${ }^{2}$ Department of Biology, Ghent University, \\ K. L. Ledeganckstraat 35, 9000 Ghent, Belgium
}

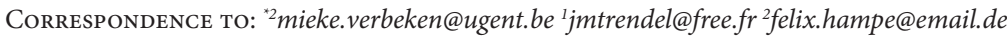

Aвstract-Based on morphological, molecular, and ecological data, a new species of Russula sect. Russula, found on several occasions under deciduous trees in Northern Alsace is described and illustrated as: Russula vinosoflavescens, belonging to $R$. subsect. Sardoninae.

KEY WORDS-Basidiomycota, Russulaceae, ITS, Russula persicina, phylogeny

\section{Introduction}

Russula Pers. (Russulales, Basidiomycota) is an ectomycorrhizal genus with a world-wide distribution that is particularly well studied in temperate regions, notably in Europe (Romagnesi 1967; Sarnari 1998, 2005). The ectomycorrhizal associations, which often involve a selective fungus-plant partnership, were sometimes advantageously used to delimit infrageneric taxa. Such has been the case for $R$. subsect. Sardoninae Singer (Sarnari 1998, emend.), which is divided into series - provisionally defined by Sarnari (1998)—comprising, on one hand, species strictly associated with conifers $(R$. ser. Sardonia and $R$. ser. Sanguinea, both essentially corresponding to $R$. subsect. Sardoninae as conceived by Romagnesi 1967, 1987) and, on the other hand, species associated with deciduous trees, sometimes in a host-specific relationship $(R$. ser. Exalbicans $=R$. subsect. Exalbicantinae Singer as retained by Romagnesi, with species found only under birches) and sometimes with a broader host-range ( $R$. ser. Persicina $=R$. subsect. Persicinae Romagn., species that can be found under oaks, hornbeams, beeches, birches, chestnuts, poplars, willows). 
TABLE 1. Russula, Gymnomyces, and uncultured specimens with GenBank and UNITE sequence accession numbers used in the molecular analyses.

\begin{tabular}{|c|c|c|c|}
\hline SPECIES & SPECIMEN & COUnTry & SEQUENCE \\
\hline G. gilkeyae & JT 2572 & USA & AY239346 \\
\hline G. monosporus & OSC 117360 & USA & EU669222 \\
\hline \multirow[t]{5}{*}{ root sample (uncultured) } & - & France & JQ890299 \\
\hline & - & - & JN197654 \\
\hline & - & USA & EF434062 \\
\hline & - & USA & GU997950 \\
\hline & - & USA & GU997948 \\
\hline R. americana & F 18871 & USA & HQ604839 \\
\hline \multirow[t]{2}{*}{ R. aquosa } & TU 101831 & Estonia & UDB015988 \\
\hline & TU 101708 & Estonia & UDB011290 \\
\hline \multirow[t]{2}{*}{ R. atrorubens } & TU 101691 & Estonia & UDB011358 \\
\hline & TU 101851 & Estonia & UDB016006 \\
\hline \multirow[t]{2}{*}{$\begin{array}{l}\text { R. bresadolae } \\
\text { (“R. atropurpurea”) }\end{array}$} & HUE 178 & Germany & UDB000313 \\
\hline & PRM 858109 & Czech Republic & HG423574 \\
\hline \multirow[t]{2}{*}{ R. cavipes } & RT 9149 & Italy & JF908681 \\
\hline & HUE 163 & Germany & AF418623 \\
\hline Russula cf. "ammodica" & F 18874 & USA & HQ604840 \\
\hline \multirow[t]{2}{*}{ R. citrinochlora } & TU 101905 & Norway & UDB016045 \\
\hline & 20024 & Sweden & UDB002550 \\
\hline \multirow[t]{2}{*}{ R. consobrina } & TU 118108 & Estonia & UDB011223 \\
\hline & TU 106965 & Estonia & UDB011207 \\
\hline \multirow[t]{2}{*}{ R. depallens } & TU 101829 & Estonia & UDB015986 \\
\hline & TU 101838 & Estonia & UDB015994 \\
\hline \multirow[t]{3}{*}{ R. emetica } & F 14309 & - & AY228360 \\
\hline & DG 18 & United Kingdom & JQ888196 \\
\hline & DG 44 & United Kingdom & UDB001628 \\
\hline R. exalbicans & 2-1117IS76 & - & AY061674 \\
\hline R. fageticola ("R. mairei") & FH 12262 & Germany & KT934013 \\
\hline R. fageticola ("R. nobilis") & HUE 054 & Germany & UDB000346 \\
\hline \multirow[t]{2}{*}{ R. fellea } & HUE 218 & Germany & UDB000345 \\
\hline & HUE 177 & Germany & UDB000314 \\
\hline \multirow[t]{2}{*}{ R. fragilis } & UE 2006-11-08-22 & Italy & UDB018436 \\
\hline & UE 2004-20-09-04 & Sweden & UDB018434 \\
\hline \multirow[t]{2}{*}{ R. gracillima } & TU 101725 & Estonia & UDB011361 \\
\hline & TU 106437 & Estonia & UDB011176 \\
\hline \multirow[t]{2}{*}{ R. luteotacta } & TU 106379 & Estonia & UDB011166 \\
\hline & FH 12-187 & Germany & КT933991 \\
\hline \multirow[t]{2}{*}{ R. ochroleuca } & TU 118113 & Estonia & UDB011228 \\
\hline & LW 115 & Germany & UDB000295 \\
\hline \multirow[t]{2}{*}{ R. persicina } & TU 101826 & Estonia & UDB015984 \\
\hline & TU 106950 & Estonia & UDB011196 \\
\hline \multirow[t]{2}{*}{ R. pumila } & F 133 & Finland & UDB009582 \\
\hline & L $3 X 87$ & - & FM993279 \\
\hline \multirow[t]{2}{*}{ R. queletii } & FH 12-237 & Germany & KT934007 \\
\hline & RT 5140 & Italy & JF908668 \\
\hline
\end{tabular}




\begin{tabular}{|c|c|c|c|}
\hline \multirow[t]{2}{*}{ R. renidens } & TU 101809 & Estonia & UDB015975 \\
\hline & JR $1758 F^{\text {IT }}$ & Finland & UDB011117 \\
\hline \multirow[t]{2}{*}{ R. rhodomelanea } & FH 2011-BT307 & Germany & UDB018429 \\
\hline & IB $92 / 451^{\mathrm{HT}}$ & Italy & UDB018435 \\
\hline \multirow[t]{2}{*}{ R. sanguinea } & TU 106710 & Estonia & UDB019728 \\
\hline & FH 12240 & Germany & KT934008 \\
\hline \multirow[t]{2}{*}{ R. sardonia } & TU 106951 & Estonia & UDB011197 \\
\hline & FH 12215 & Germany & KT933999 \\
\hline \multirow[t]{2}{*}{ R. silvestris } & JK 11080504 & Sweden & UDB018431 \\
\hline & JK 11080802 & Sweden & UDB018430 \\
\hline R. thindii ${ }^{\mathrm{HT}}$ & BSHC KD11-095 & India & KM386693 \\
\hline \multirow[t]{2}{*}{ R. torulosa } & TU 106444 & Estonia & UDB011177 \\
\hline & TU 101626 & Italy & UDB016261 \\
\hline \multirow[t]{6}{*}{ R. vinosoflavescens } & JMT 05081006 & France & UDB031189 \\
\hline & JMT 08081512 & France & UDB031188 \\
\hline & JMT $14090502^{\text {HT }}$ & France & UDB031187 \\
\hline & JMT 05081007 & France & UDB031190 \\
\hline & JMT 10080701 & France & UDB024104 \\
\hline & JMT 13090715 & France & UDB024105 \\
\hline \multicolumn{4}{|l|}{ Outgroup } \\
\hline R. puellula ("R. puellaris") & MC 01-502 & Denmark & UDB000010 \\
\hline R. cuprea & FH 12250 & Germany & KT934010 \\
\hline R. olivobrunnea & TU 101883 & Finland & UDB016034 \\
\hline
\end{tabular}

${ }^{\mathrm{HT}}$ holotype; ${ }^{\mathrm{IT}}$ isotype.

The aim of this paper is to introduce a new Russula species occurring in deciduous forests of Northern Alsace (NE France) and belonging to $R$. subsect. Sardoninae. Our initial morphological concept of the species, based on several collections from various localities, is fully supported by molecular data. ITS sequence analysis shows that the different collections form a well-supported clade in the Russula phylogenetic tree.

\section{Materials \& methods}

\section{Sampling}

All collections of the new taxon were made by Jean Michel Trendel and are deposited in GENT Herbarium. These collections are referred to with an eight-digit code YYMMDDXX (year; month; day; collection number). All collecting sites are located in Northern Alsace (NE France); the code of the municipality is that assigned by the National Institute for statistics and economic studies (INSEE); names (in quotation marks) of forest or place are those indicated on the topographic maps (1:25000 scale) from the Institut national de l'information géographique et forestière (IGN); map coordinates of the collections refer to the Universal Transverse Mercator (UTM) $32 \mathrm{~N}$ kilometer grid system; geological data (underlying rock) were mainly obtained 
from geological maps (1:50000) edited by the Bureau de Recherches Géologiques et Minières (BRGM).

\section{Morphological analysis}

Specimens were photographed in situ. The pictures are available at http://www2.muse.it/russulales-news/. Microscopic observations were carried out on fresh material. Pileipellis elements were studied on radial sections made by hand midway from the cap margin, mounted either in SDS Congo red (Clémençon 1999) or in distilled water. The search for acido-resistant encrustations was performed by staining with Ziehl carbol fuchsin followed by a rapid differentiation using a $1 \mathrm{M} \mathrm{HCl}$ solution. Pileocystidia content was revealed using sulfovanillin (SV) freshly prepared with a $50 \%$ or $80 \% \mathrm{H}_{2} \mathrm{SO}_{4}$ aqueous solution. Hymenial elements were studied in the above-mentioned observation media. In some cases, additional controls were carried out on very fine cap sections made from dried material and further rehydrated in a moisture-saturated closed chamber for $24 \mathrm{~h}$ before observation in water. Basidiospores (from spore deposits) were examined in Melzer's reagent and spore measurements (ornamentation excluded) were recorded randomly for 300 spores (6 collections) in side view. Measurements are given as $(\mathrm{MINa})\left[\mathrm{AVa}-2{ }^{\star} \mathrm{SD}\right]-A v a-A V b-\left[\mathrm{AVb}+2{ }^{\star} \mathrm{SD}\right]$ $(\mathrm{MAXb})$, with $\mathrm{AVa}=$ lowest mean value for the measured collections and MINa the minimum value corresponding with this mean value, $\mathrm{AVb}=$ greatest mean value and MAXb the maximum value corresponding with this mean value, and $\mathrm{SD}=$ standard deviation calculated for the measurements of one collection (minimum and maximum value are only given if not in the $2 * \mathrm{SD}$-interval). Q stands for spore "length/width ratio" and is given as (MINQa)-Qa-Qb-(MAXQb) with Qa and Qb being the lowest, and the highest respectively, mean ratio for the measured specimen. The colour of the spore deposit, referring to Romagnesi's (1967) scale, was assessed against a personal chart (JMT) and the Dagron's chart (unpublished). Macrochemical reactions were determined using $\mathrm{FeSO}_{4}$ in crystalline form, a $4 \%$ phenol solution, and a strong Guaiac solution made of permanently soaked Guaiac wood in $95 \%$ ethanol.

\section{Molecular analysis}

Total genomic DNA was extracted from dried material according to Nuytinck \& Verbeken (2003), with modifications described in Van de Putte et al. (2010). The ITS region was amplified using the primers ITS1F-ITS4 (White et al. 1990, Gardes \& Bruns 1993) and with polymerase PerfectTAQ (5 PRIME, Hilden, Germany) in accordance with the manufacturer's recommendation. PCR amplification followed Eberhardt (2012), and the PCR products were purified using the Qiaquick PCR Purification Kit (Qiagen, Hilden, Germany) and directly sequenced with BigDye 3.1 technology (Applied Biosystems, now Thermo Fisher Scientific, Wilmington, USA). Specimens JMT-05081006, JMT-05081007, and JMT-05081512 were extracted and sequenced in Muséum National d'Histoire Naturelle de Paris (Marc-André Selosse) following Séne et al. (2015).

Raw sequences were edited in the BioEdit Sequence Alignment Editor version 7.2.5 (Hall, 2013) or Sequencher version 4.8 (Gene Codes Corporation). Edited sequences 
were aligned by MAFFT version 7 using the strategy E-INS-i (Katoh \& Standley 2013). Maximum-likelihood searches for tree building were carried out locally with 100 replicates with the GTR+GAMMA model, selecting the best solution of all replicates analysis in RaXML 8.1.12 (Stamatakis 2014). Fast bootstrap searches were done locally or through the CIPRES Science Gateway (Miller et al. 2010) with 10000 replicates.

The final alignment included a total number of 67 ITS sequences, with 21 sequences corresponding to the current concept of $R$. subsect. Sardoninae (Sarnari 1998). Except for the $R$. vinosoflavescens collections cited as studied material all sequences were retrieved from GenBank or UNITE (TABLE 1). The tree with the highest log likelihood $(-4523.1303)$ is shown. Initial tree(s) for the heuristic search were obtained automatically by applying the Maximum Parsimony method.

\section{Taxonomy}

Russula vinosoflavescens Trendel \& F. Hampe, sp. nov.

Figures 1, 2

MycoBank MB 819428

Differs from Russula persicina by its colour range, its mild or only slightly acrid taste, its reticulate spore ornamentation, and the presence of granular pigments in cuticular hyphae.

Type: France, Alsace, Morsbronn-les-Bains (67303), "Niederwald", UTM 32N: 0406318/5419158, $213 \mathrm{~m}$ alt., on argillaceous soil with eumull humus (underlying rock: upper Keuper red marls), under Quercus robur and Carpinus betulus with some Fagus sylvatica nearby, in an area characterized by calcicolous mycoflora with numerous Phlegmacium (Cortinarius) species, 5 Sept. 2014, JMT-14090502 (Holotype, GENT; UNITE UDBo31187).

Eтүмоlogy: Referring to the purplish-red wine-coloured (vinoso) cap and the tendency of the cap to become brown-yellowish or ochraceous (flavescens) as well as when handling the stipe.

Pileus 4.0-6.5 cm diam., more or less fleshy, rather firm to very firm but with margin occasionally slightly elastic, often irregular, at times knotty, convexflattened with the margin sometimes incurved or even inrolled, then broadly but shallowly depressed; margin not or shortly sulcate, often flexuose-undulate or lobed, in some cases showing a very clear, whitish border extending to the edge of the gills (giving a "festooned" appearance); surface rugulose, more or less radially veined, frequently uneven-bumpy in the centre, a little shiny in wet conditions, but soon dry (except sometimes in the centre which remains a little greasy) and then more mat, purple-red, carmine-red, vinaceous-red, somewhat violet, rather vivid, but frequently paler, livid pinkish-vinaceous, with mauve (lilac) greyish shades that can entirely replace the reddish tinges, even more clearly greyish purple at the margin, becoming yellowish cream-ochraceous from the centre or showing locally ochre-bistre areas merging in the reddish and greyish mauve tints, sometimes becoming almost totally beige-brown, 
ochreous-brown, with livid purple-violet glints mostly near the margin and a residual purple-brown at centre. LAMELLAE adnate or attenuated-subdecurrent, sometimes sub-emarginate, with a variable number of lamellulae, crowded to rather spaced, interveined, anastomosing and more or less forked at every level, in some cases more particularly near the stem (exceptionally regular, without any forking or anastomosing), (sub)acute at the cap margin (rarely subobtuse), narrow $(0.3-0.5 \mathrm{~cm}$, exceptionally broader $\leq 0.7 \mathrm{~cm})$, whitish or very pale cream; edge entire but often somewhat irregularly wavy. STIPE 2-6× $0.9-1.5(-2) \mathrm{cm}$, cylindrical or slightly enlarged downwards, usually rounded at the base (in a few cases tapering), sometimes eccentric, firm to almost hard, with a firm medulla (exceptionally hollow-fistulous); surface nearly smooth, finely wrinkled, white with occasionally a purple tinge (in one case remarkably grey-purplish, somewhat brownish), distinctly yellowing (dirty, often with greyish-brown shades) when handled or bruised. ConTExT white, in the pileus almost unchanging, in medulla of stipe slightly yellowing, sometimes a little purple-violet beneath the cuticle in the most coloured forms; taste mild (or almost mild, occasionally with an unpleasant aftertaste, somewhat bitter), mild to slightly (and sometimes volatile) acrid in the gills, exceptionally more strongly acrid; smell not distinctive.

Macrochemical Reactions $\mathrm{FeSO}_{4}$ : rose-orange; Phenol: brown; Guaiac: in most cases reacting on the stem surface almost immediately $(<2 \mathrm{~s}$, in one case more slowly), but of little intensity at the beginning, developing (10-15 s) in blue of medium intensity, exceptionally with a stronger reaction, (dark blue); on gills, the reaction developing slowly and weakly (blue-green to light blue).

SPORE PRINT cream, II(a)b-c.

BASIDIOSPORES subglobose to broadly ellipsoid, 6.4-7.2-8.1-9.0 × 5.9-6.56.9-7.7 $\mu \mathrm{m}(\mathrm{n}=300), \mathrm{Q}=1.06-1.11-1.20-1.30$; ornamentation amyloid, often with incompletely amyloid warts; warts conical-obtuse, or more acute, sometimes somewhat truncated, generally around $0.4-0.8 \mu \mathrm{m}$ high, but also frequently reaching $1.0 \mu \mathrm{m}$ or higher, sometimes locally catenulate, interconnected by crests or more frequently by (often very fine) connectives, forming a well-developed and often nearly complete (with numerous meshes) reticulum, which may appear confused in some cases; suprahilar plage moderately amyloid, more or less bordered by small warts or low crests. BAsIDIA 4-spored, 42-57 $\times 9.5-12.5 \mu \mathrm{m}$, including sterigmata (about $5 \mu \mathrm{m}$ long). Pleuromacrocystidia 60-90 × 10.5-14.5 $\mu \mathrm{m}$, numerous, fusiform or more or less clavate, most commonly with a pointed appendage, which can show constrictions, more rarely ending in a short obtuse protuberance, 

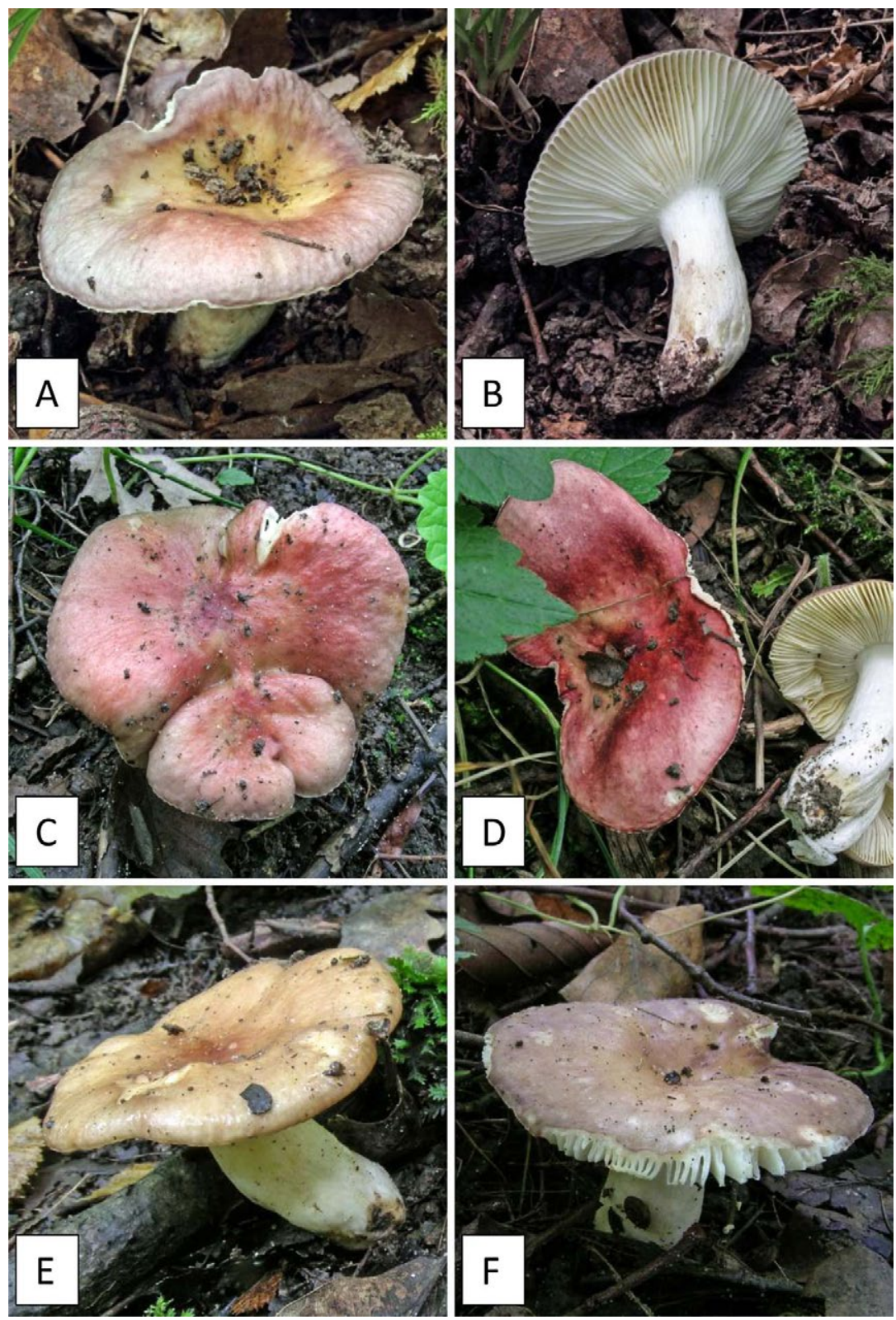

FIG. 1. Russula vinosoflavescens: colour forms observed. A, B. holotype, collection JMT-14090502; C. collection JMT-05082042, with marked reddish pigmentation; D. collection JMT-05081006, with marked reddish pigmentation; E. collection JMT-08081512, with predominating ochraceous colour; F. collection JMT-10080701, with mauve-lilac colour reminiscent of a Griseinae. 
strongly staining with SV. PILEIPELLIS composed of hyphae containing reddishviolaceous granular pigments; epicuticular elements (2.0-)2.5-4.0 $\mu \mathrm{m}$ diam., sometimes branched, flexuose, sometimes inflated up to $5.5 \mu \mathrm{m}$; terminal cell obtuse, or slightly thickened with a short appendage, also subcapitulate, or (exceptionally) pear-shaped $\leq 7.0 \mu \mathrm{m}$ diam., but also conversely more or less attenuated (sometimes abruptly). Pileocystidia of two types; type 1 usually unicellular (occasionally with 1 septum), rarely bifid, clavate-fusiform, less frequently cylindric, 4.0-9.5 $\mu \mathrm{m}$ diam., often appendiculate-capitulate or showing an obtuse apical protuberance, sometimes slender, (at least $120 \mu \mathrm{m}$ long, narrowed at the base to 2.5-3.0 $\mu \mathrm{m}$ diam.), with a content reacting variably depending on the collection-but also on a cuticular section-when treated with SV, staining (rather) strongly (grey-blackish) or weakly (grey-pinkish) or even remaining inert (pinkish); type 2 lactiferoid (some clearly termini of ascending lactifers), pluriseptate, more or less regularly cylindrical, 6.0-10.5 $\mu \mathrm{m}$ diam., with variably shaped terminal elements that sometimes taper (with possible constrictions), sometimes are somewhat thickened or subclavate, or with type 1 type appendages, originating in the deeper pellis, distinctly reacting with SV (except in one specimen where the granular content of pileocystidia type 2 is inert or reacts only very weakly in SV); without encrusted elements after treatment with Ziehl fuchsin.

ECOlOGY \& Distribution-Under deciduous trees, associated with Carpinus betulus, or Quercus (Q. robur or Q. petraea), or both (possibly also with Fagus sylvatica), in a rather wet environment (possibly periodically drier), on more or less argillaceous soils, neutral to superficially slightly acidic, usually nutrient-rich with a rather high base saturation level (calcium-rich), with mesotrophic to eutrophic mull humus. Phenology: late July to early September (summer fruiting). Known only from six sites ( 9 collections) in Northern Alsace (France).

Additional specimens examined-FRANCE, Alsace. Bas-Rhin, Mattstall, commune associated with Lembach (67263), 'Sauerhald', UTM 32N: 0409918/5426543, alt. $203 \mathrm{~m}$, underlying rock: Upper Muschelkalk marly calcareous formation, under Quercus, Carpinus, Fagus (forest locally rich in orchids, e.g., Epipactis microphylla), JMT-13090715 (GENT, UNITE: UDB024105); Dauendorf (67087), 'Herrenwald', 0402753/5410066, $168 \mathrm{~m}$, Loess from the Quaternary (and more ancient alluvial deposits?), in a wet environment, nitrogen-rich and with a high base saturation level, under Carpinus, Quercus, Alnus glutinosa, Fraxinus excelsior, Ulmus sp., and with a herbaceous layer comprising Allium ursinum, Carex sylvatica, Circaea lutetiana, Geum urbanum, Glechoma hederacea, Paris quadrifolia, Stachys sylvatica, JMT-10080701 (GENT, UDB024104); 0402762/5409965, $171 \mathrm{~m}$, Loess from the Quaternary (and more ancient alluvial deposits?), under Carpinus, Quercus, JMT-05082042 (GENT); 

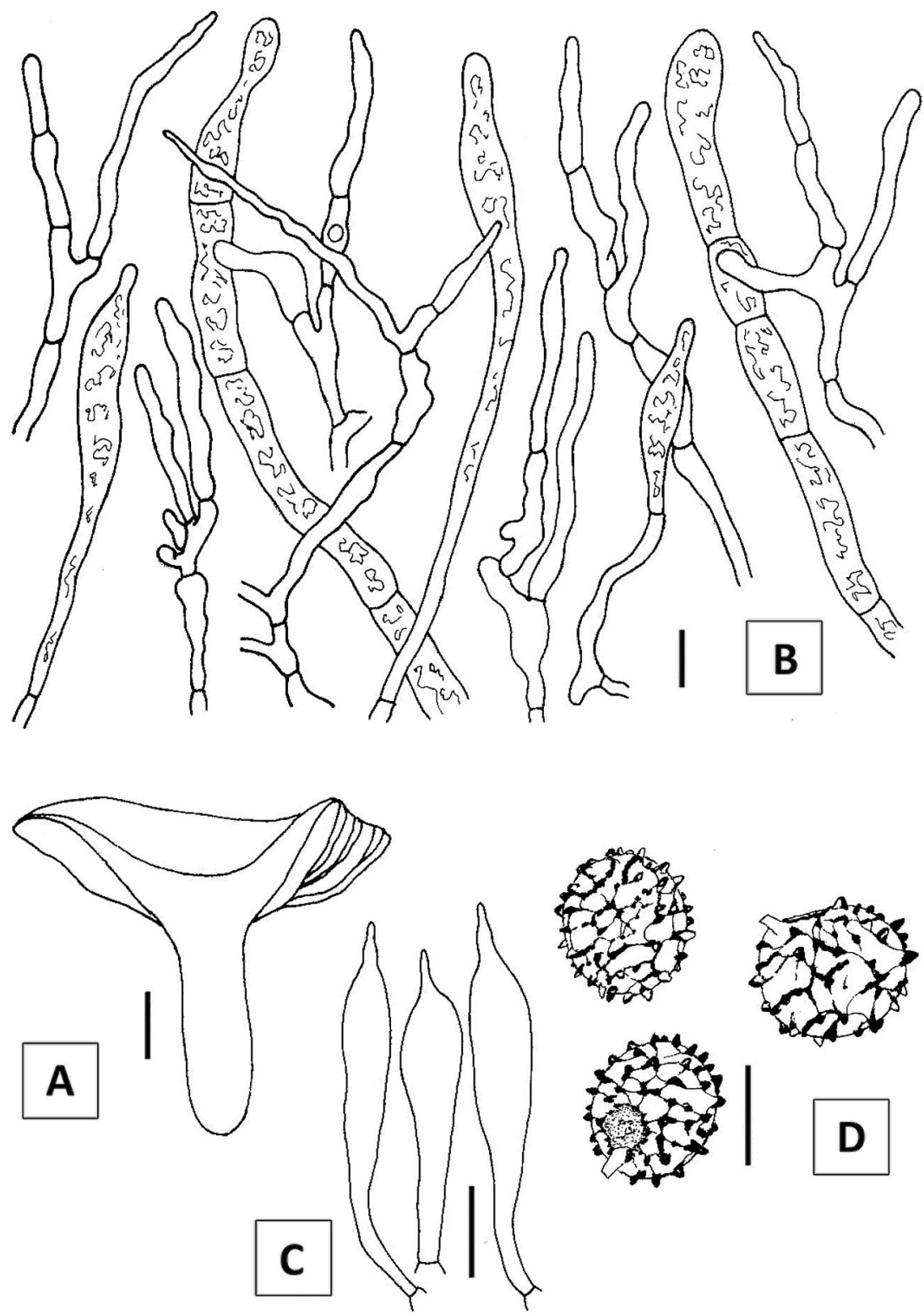

FIG. 2. Russula vinosoflavescens (holotype, collection JMT-14090502). A. fruitbody in sectional view; B. pileus epicutis: pileocystidia (with content shown schematically) and hyphal terminal elements; C. hymenial cystidia on gill sides; D. spores as observed in Melzer's reagent. Scale bars: $\mathrm{A}=1 \mathrm{~cm} ; \mathrm{B}=10 \mu \mathrm{m} ; \mathrm{C}=20 \mu \mathrm{m} ; \mathrm{D}=5 \mu \mathrm{m}$. 
Bettwiller (67036), 'Buchwald', 0365394/5416535, 347 m, Upper Muschelkalk marly calcareous formation, under Quercus, Carpinus, with some Fagus and Prunus avium, JMT-05081006 (GENT, UDB031189) and JMT-05081007 (GENT, UDB031190), most likely belonging to the same mycelium; Forstheim (67141), 'der Wald', 0405631/5415509, $211 \mathrm{~m}$, Pliocene sands and clays, wet environment, under Quercus, Carpinus, Populus tremula with Russula lutensis Romagn. and R. rutila Romagn., JMT-08081512 (GENT, UDB031188); Drusenheim (67106), 'Barrwald', approximately 0420900/5401000, 124 m, Quaternary alluvial deposits, wet environment, on bare blackish ground, with Carpinus, Quercus, Alnus glutinosa, Fraxinus excelsior, 25/07/1981, JMT-81072501 (GENT, spore print only available).

\section{Discussion}

\section{Molecular analysis}

The six ITS sequences of the newly described $R$. vinosoflavescens form an independent clade, which receives high bootstrap support (FIG. 3). The clade corresponding to $R$. vinosoflavescens is nested within a large, supported (bootstrap value 75) clade that includes the typical European representatives of $R$. subsect. Sardoninae ( $R$. sardonia Fr., $R$. queletii Fr., $R$. torulosa Bres.). Beside these, it contains a number of species (e.g., $R$. cavipes Britzelm., $R$. exalbicans (Pers.) Melzer \& Zvára, R. gracillima Jul. Schäff., R. luteotacta Rea, R. persicina Krombh., $R$. renidens Ruots. et al., $R$. sanguinea Fr.) included by Sarnari (1998) in his emended concept of $R$. subsect. Sardoninae but attributed to different (although closely related) infrageneric taxa by previous authors (Romagnesi 1967, Singer 1986, Bon 1988). In addition to the abovementioned species, which fairly well represent $R$. subsect. Sardoninae sensu Sarnari, the clade includes extra-European Sardoninae species such as R. thindii K. Das \& S.L. Miller and some poorly known species with an uncertain systematic position (e.g., R. americana Singer, R. citrinochlora Singer).

The deeper phylogenetic relationships within the Sardoninae clade as well as its external relationships with $R$. fellea (Fr.) Fr., R. consobrina (Fr.) Fr., $R$. ochroleuca Fr., and the large clade representing $R$. subsect. Russula s.l. (including a sequence of the generic type $R$. emetica (Schaeff.) Pers.) remain poorly resolved in the ITS analysis. Within the Sardoninae clade, $R$. vinosoflavescens occupies a rather isolated position in a weakly supported subclade containing $R$. renidens and samples identified as $R$. citrinochlora.

\section{Morphological analysis}

Despite its mild taste (in most cases only weakly acrid in gills), R. vinosoflavescens shows a combination of characters-a more or less fleshy firm pileus, cuticle often rugulose with polychromic colours, cream spore 


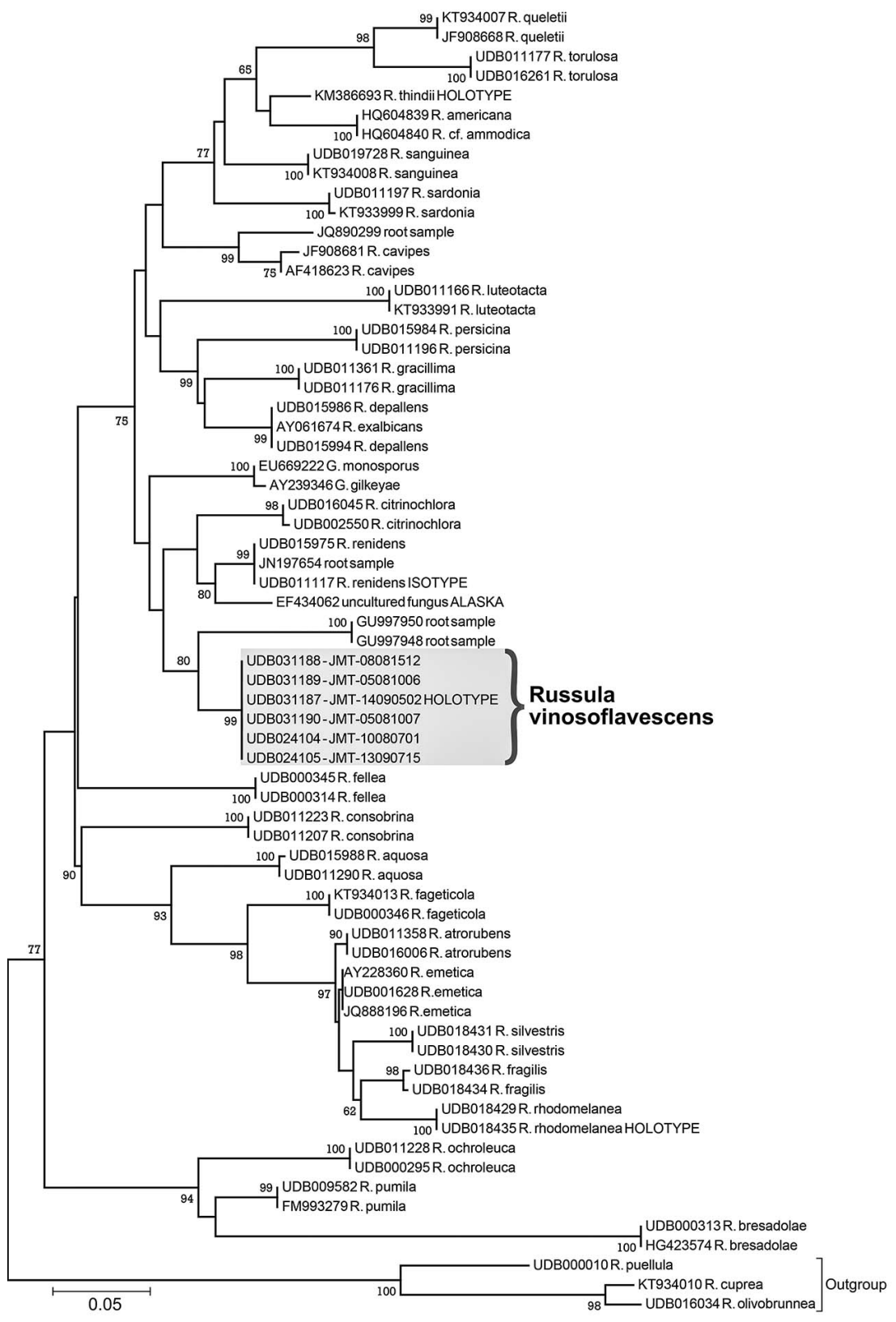

FIG. 3. Molecular phylogenetic analysis by Maximum Likelihood method-based tree with the highest log likelihood (-4523.1303), based on ITS sequences. 
print, well-characterised and non-encrusted pileocystidia-that is consistent with its position in $R$. subsect. Sardoninae sensu Sarnari. Moreover, by its habitus, somewhat decurrent narrow gills, and clear yellowing of its stipe when bruised, this species is very reminiscent of certain forms of R. persicina. Russula vinosoflavescens differs, however, unambiguously from the latter by its colours, which are never 'pure' red. Indeed, even in its reddest forms, the cap always displays some purple-vinaceous tinges, presumably reflecting the existence of one or several blue pigments, occurring in sufficient amount to significantly shade the red ones. The presence of these blue pigments becomes even more apparent when grey-mauve (lilac) tints replace-sometimes completely-the reddish colouring. In addition, this russula appears to fade readily to yellowish ochre, or even brown-beige, and therefore colour forms devoid of any reddish or bluish shades might be expected.

Other striking features are the often rugulose surface of the cuticle and the strong tendency of the lamellae to become anastomosed-forked, though it should be kept in mind that these characters are variable. The same is true for the variability of the speed and intensity of the Guaiac reaction, which is mostly in an average position on the reactivity scale.

One of the most striking microscopical features is the aggregation of pigments into granules (sometimes distinctly combining red and blue pigments) that are generally easily observed in the cap cuticular hyphae. The cuticular structure of specimens for which we were unable to examine in fresh condition was re-examined in dried material. Concerning the least pigmented collection JMT-08081512 (Fig. 1-E), cuticular sections from the central part of the cap-apparently the richest in residual red and blue pigments-revealed the presence of pigmented grains. Our search was much less conclusive for the vividly coloured specimens JMT-05081006 (FIg. 1-D), and even if we were able to show the presence of sparse coloured granules, it appears that a significant amount of pigment is either vacuolar (soluble) or at least not distinctly granular. In addition, examination of the cuticle of collection JMT-05082042 (FIg. 1-C), not studied in a fresh state, clearly revealed the presence of pigmented granules.

As reported by Romagnesi (1967) and Sarnari (1998), granular pigments are highly characteristic of $R$. subg. Heterophyllidia but are also found occasionally in some species belonging to other groups. In this respect, one should especially mention $R$. renidens, a Nordic russula growing under birches, which shows abundant granular red-purplish pigments, the latter probably co-occurring in a soluble form accounting for the intensity of its colours (Sarnari 1998). A similar situation may also exist for some of our vividly coloured collections 
(notably JMT-05081006 and JMT-05081007). Indeed, it seems likely that pigment aggregates contribute less efficiently to global colouring compared to those in solution, and that a strong predominance of granular pigments over their soluble counterparts may explain the relative paleness of some of our collections.

The morphology of the terminal hyphal cells of the epicuticular elements appears too variable to be usable for species recognition. On the other hand, pileocystidial shape seems informative at species level. It is also significant that this characteristic can be found in almost all members of $R$. subsect. Sardoninae as defined by Sarnari, where the new species belongs.

Another important diagnostic feature is the strongly reticulate spore ornamentation that distinguishes $R$. vinosoflavescens from similar species sharing the same cream spore print and also growing under deciduous trees, such as $R$. persicina or the birch associates, $R$. exalbicans and $R$. renidens.

\section{Ecology}

Within Russula subsect. Sardoninae, partitioned by Sarnari (1998) into ecological series based on Russula/tree partnerships, $R$. vinosoflavescens fits in $R$. ser. Persicina, devoted to species associated with broadleaf trees (but not strictly with birches); the other series cover species linked strictly to either conifers ( $R$. ser. Sardonia and R. ser. Sanguinea) or birches ( $R$. ser. Exalbicans). Indeed, $R$. vinosoflavescens appears associated with oak (Quercus robur or Q. petraea) or hornbeam (Carpinus betulus) or both, the only trees present on all collecting sites. A wider host association might include beech (Fagus sylvatica, generally well represented in the forests of interest but sometimes rather far away from the fruiting bodies) or, less likely, aspen (Populus tremula, which can occur in more complex environments). Birch (Betula spp.), absent from all the prospected sites, should not be considered a potential associate. However, regarding Romagnesi's (1967) initial concept of Persicinae, which refers to "intermediate forms between Emeticinae and Sardoninae [both sensu Romagnesi!], with less reticulate spores and gills more decurrent or weeping than the former, and more purely red in colour than the latter" [a concept at least partly shared by Sarnari (1998) - "pileus pure red"], it becomes necessary to restrict Sarnari's $R$. ser. Persicina definition exclusively to ecology, as in $R$. vinosoflavescens colouration is not restricted to pure red and its spores are rather strongly reticulate. In his classification, Bon (1988) does not retain Romagnesi's Persicinae group but treats the different taxa of $R$. persicina in his emended $R$. subsect. Exalbicantinae. In this context, $R$. vinosoflavescens would take its place beside R. exalbicans, which also often displays washed-out greyish 
colours, and $R$. renidens, genetically a very closely related species sharing some outstanding morphological features such as pigments that are at least partly granular or lamellae that are more or less forked.

\section{Acknowledgments}

We are extremely thankful to Josie Lambourdière and Prof. Marc-André Selosse (Muséum national d'Histoire Naturelle, Paris) for some additional molecular analyses, and to Dr. Philippe Schaeffer for helpful discussions. Dr. Ursula Eberhardt and Geoffrey Kibby are acknowledged for useful comments and reviewing the paper.

\section{Literature cited}

Bon M. 1988. Clé monographique des russules d'Europe. Doc. Mycol. 18(70-71): 1-120.

Clémençon H. 1999. Vom Umgang mit Kongorot. Schweiz. Z. Pilzk. 77(5): 247-250.

Eberhardt U. 2012. Methods for DNA barcoding of fungi. 183-205, in: WJ Kress, DL Erickson (eds). DNA Barcodes: Methods and Protocols, Methods in Molecular Biology, vol. 858. New York, Humana Press. https://doi.org/10.1007/978-1-61779-591-6_9

Gardes M, Bruns TD. 1993. ITS primers with enhanced specificity for basidiomycetes application to the identification of mycorrhizae and rusts. Mol. Ecol. 2(2): 113-118. https://doi.org/10.1111/j.1365-294X.1993.tb00005.x

Hall T. 2013. BioEdit, Biological sequence alignment editor for Windows 5/98/NT/2000/XP/7, version 7.2.5. Ibis Biosciences, Carlsbad. https://www.mbio.ncsu.edu/bioedit/bioedit.html (accessed 15 March 2016).

Katoh K, Standley DM. 2013. MAFFT multiple sequence alignment software version 7: improvements in performance and usability. Mol. Biol. Evol. 30(4): 772-780.

https://doi.org/10.1093/molbev/mst010

Miller MA, Pfeiffer W, Schwartz T. 2010. Creating the CIPRES Science Gateway for inference of large phylogenetic trees. 1-8, in: Proceedings of the Gateway Computing Environments Workshop (GCE), 14 Nov. 2010, New Orleans, Louisiana. https://doi.org/10.1109/GCE.2010.5676129

Nuytinck J, Verbeken A. 2003. Lactarius sanguifluus versus Lactarius vinosus - molecular and morphological analyses. Mycol. Progress 2(3): 227-234.

https://doi.org/10.1007/s11557-006-0060-5

Romagnesi H. 1967. Les Russules d’Europe et d’Afrique du Nord. Paris, Bordas.

Romagnesi H. 1987. Statuts et noms nouveaux pour les taxa infragénériques dans le genre Russula. Doc. Mycol. 18(69): 39-40.

Sarnari M. 1998. Monografia illustrata del Genere Russula in Europa, vol 1. Vicenza, Associazione mycologica Bresadola (AMB), Fondazione Centro studi micologici.

Sarnari M. 2005. Monografia illustrata del Genere Russula in Europa, vol 2. Vicenza, Associazione mycologica Bresadola (AMB), Fondazione Centro studi micologici.

Séne S, Avril R, Chaintreuil C, Geoffroy A, Ndiaye C, Diédhiou AG, Sadio O, Courtecuisse R, Sylla SN, Selosse MA, Bâ A. 2015. Ectomycorrhizal fungal communities of Coccoloba uvifera (L.) L. mature trees and seedlings in the neotropical coastal forests of Guadeloupe (Lesser Antilles). Mycorrhiza 25: 547-559. https://doi.org/10.1007/s00572-015-0633-8

Singer R. 1986. The Agaricales in modern taxonomy. Königstein, Koeltz Scientific Books.

Stamatakis A. 2014. RAxML version 8: a tool for phylogenetic analysis and post-analysis of large phylogenies. Bioinformatics 30(9): 1312-313. https://doi.org/10.1093/bioinformatics/btu033 
Van de Putte K, Nuytinck J, Stubbe D, Le HT, Verbeken A. 2010. Lactarius volemus sensu lato (Russulales) from northern Thailand: morphological and phylogenetic species concepts explored. Fungal Diversity 45(1): 99-130. https://doi.org/10.1007/s13225-010-0070-0

White TJ, Bruns T, Lee S, Taylor J. 1990. Amplification and direct sequencing of fungal ribosomal RNA genes for phylogenetics. 315-322, in: MA Innis et al. (eds). PCR Protocols: a guide to methods and applications. San Diego, Academic Press.

https://doi.org/10.1016/b978-0-12-372180-8.50042-1 